\title{
Examination of the vibroacoustic behavior of a grid-stiffened panel with applied passive constrained layer damping
}

\author{
Maik Titze*, Malte Misol, Hans Peter Monner \\ German Aerospace Center, Institute of Composite Structures and Adaptive Systems, \\ Department of Adaptronics, Lilienthalplatz 7, 38108 Braunschweig, Germany
}

\begin{abstract}
This paper provides a contribution to the understanding of both the vibroacoustical behavior and the influence of passive constrained layer damping (PCLD) applications on the sound radiation of a grid-stiffened panel. A test specimen is manufactured and an experimental set-up with a synthetic turbulent boundary layer excitation is developed. In addition, a numerical model is created and updated with the results of an experimental modal analysis. Further, the acoustic effect of PCLD applied to the ribs and to the skin fields of the grid panel is assessed by measurement of the radiated sound power. It is shown that the ribs are suitable for an efficient application of PCLD. Generally, additional damping of the grid panel is achieved with PCLD for frequencies above $300 \mathrm{~Hz}$. By partially covering the ribs with PCLD, a reduction of the radiated sound power of up to $2 \mathrm{~dB}$ in third-octave bands is achieved. In case of a total coverage of the grid panel, a reduction of up to $4 \mathrm{~dB}$ in third-octave bands is attained.

Keywords: grid panel, constrained layer damping (CLD), turbulent boundary layer (TBL), passive damping, isogrid, lattice fuselage structure
\end{abstract}

\footnotetext{
${ }^{*}$ Corresponding author

Email address: maik.titze@dlr.de (Maik Titze)
} 


\section{Introduction}

Grid-stiffened panels seem to be an appropriate solution regarding the increasing lightweight requirements for future aircraft structures. The design and mechanical properties of such structures are widely discussed in literature. In 5 contrast, the vibroacoustical behavior and measures to influence the radiated sound power are barely considered. Taking into account that, particularly for lightweight and stiff structures, an increased noise input to the passenger cabin can be expected, adequate countermeasures need to be taken.

The research on grid-stiffened structures originated in architecture and rocket science and was transferred to aircraft structures. A short overview of the development and application of anisogrid lattice structures is given by Vasiliev et al. in [1. Vasiliev et al. played a substantial role in shaping the research field for grid-stiffened aircraft fuselage structures and developed a realistic design of a full-scale fuselage segment [2, 3, 4, which forms the basis of this work. Other research approaches focused on the topology optimization of such aircraft structures [5]. Research on the vibroacoustical behavior of grid-stiffened structures is seldom addressed in literature. In references [6, 7, 8, general acoustical properties of geodesic stiffened structures like the sound radiation, the radiation efficiency and the sound insulation are examined. These properties are compared to the ones of flat plates and fuselage structures made from metal. It is shown that the orientation as well as the specific design of geodesic structures is less important for the vibroacoustic behavior than the stiffness-to-mass ratio. Thus, geometric optimizations aiming to improve the vibroacoustic behavior of grid-stiffened structures seem to be less promising. Only Drake [8] discussed 25 the impact of different damping techniques on the dynamic properties of a grid panel. But these studies concentrated on the application of damping materials to the panel skin. In this way it is shown that the applications of additional damping material to the skin has little effect on the transmission loss of such structures. In literature, the ribs of grid panels have not been considered so far as possible points of application for additional damping. This approach is 
followed in the present contribution. In this work, which is based on [9], the acoustic effect of passive damping measures applied to the ribs is quantified and contrasted to the established approach of skin field damping.

The structure of the work conducted in this research is presented in Figure 1.

35 First, a grid panel from aluminum is manufactured and a detailed computeraided design (CAD) model of the test specimen is created. Based on the CAD model a numerical model is developed inside Ansys and updated with the results of an experimental modal analysis (EMA). For the evaluation of the damping effect of the applied passive constrained layer damping (PCLD), the turbulent boundary layer (TBL) is chosen as load case. This excitation source is imitated in an experimental set-up using a loudspeaker array. Subsequently, the influence of different configurations of PCLD coverage on the grid panel regarding the radiated sound power is assessed.

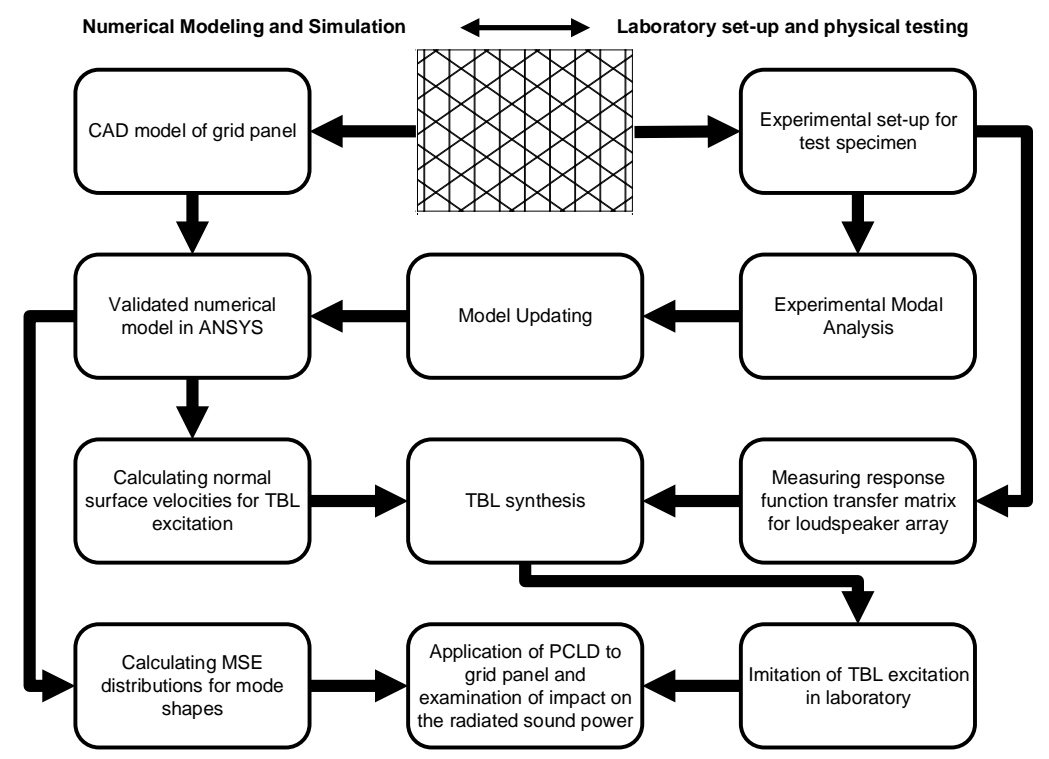

Figure 1: Schematic of the workflow and the interaction of numerical simulation and experimental investigation 


\section{Numerical modeling and experimental set-up}

45 This section provides a description of the development of the numerical model as well as of the experimental set-up. The quality of both the numerical model and the synthetic TBL excitation is discussed and basic assumptions concerning the representativeness of the results are made.

\subsection{Examination object and conditions}

50

The test specimen used for the further research is based on the design of Vasiliev in [4] and is shown in Figure 2 The geometric properties are listed in table 1. The grid panel is made of aluminum instead of carbon fiber reinforced plastics (CFRP) and manufactured in the form of a flat plate in place of a curved fuselage structure. These simplifications are considered a reasonable trade-off between costs and experimental effort on the one side and similarity to the real aircraft on the other side. Furthermore, the described methods are generally applicable to more realistic fuselage structures as well. The use of metal instead of CFRP decreases the ratio of stiffness and mass and hence will increase the acoustic coincidence frequency. Due to its lower coincidence frequency, a CFRP panel would radiate low-frequency sound more efficiently than an aluminum panel. Furthermore, the neglected curvature has an effect on the structural dynamics and the radiation impedance. The eigenfrequencies of a curved panel are shifted upwards due to the increased bending stiffness and the radiation resistance is influenced not only by monopole but also by dipole effects [10, Eq. (4.25)]. Regarding the application of PCLD to structural parts of the grid panel it is important to capture the size and geometry of the skin fields and the ribs. Although the curvature is neglected, this requirement is fulfilled. Compared to a classical fuselage panel, the skin fields of a grid panel are small and local modes will occur at higher frequencies. The lower order modes, which are of interest here, are controllable via the ribs. This is different to classical fuselage panels having relatively large skin fields (extending between two frames and two stringers). In this case local modes are excited by 
the TBL at relatively low frequencies and those modes are difficult to damp via the stiffeners. Therefore, in [11, actuators had to be bonded to the skin fields to achieve control authority over the local modes.

The manufacturing is done by laser cutting each rib, slitting them at the connection with the other ribs, putting the whole rib structure together and glueing it. The structure is afterwards glued to an aluminum plate. Adekit A170 BK is used as adhesive. The final structure has 140 skin areas and 121 rib connections.

so It is assumed that these simplifications do not affect the general transferability of the results to a realistic fuselage structure. As load case for the evaluation of the damping efficiency of constrained layer damping (CLD) applications, a synthetic TBL excitation is chosen. This is one of the most important sources for noise input into the passenger cabin during a cruising flight. It describes a broadband excitation with high amplitudes especially in the low frequency range. Because of its low spatial correlation (see Figure 7) the excitation is not mode selective, meaning that all structural modes are excited strongly. Therefore, this load case is considered as a worst case for noise control because of the high amplitudes at low frequencies combined with a very low temporal and spatial correlation. A frequency range of $100 \mathrm{~Hz}$ to $500 \mathrm{~Hz}$ is considered for the investigations. The choice of the lower bound of this range is guided by the occurrence of the first elastic mode above $100 \mathrm{~Hz}$ (see Section 2.2) and the upper bound is given by the TBL syntesis capabilities of the experimental set-up. Furthermore, the efficiency of passive damping treatment usually decreases at low frequencies which raises the demand for efficient solutions in the selected frequency range. 
Table 1: Geometric and material properties of the grid panel structure

\begin{tabular}{lr} 
Parameter & Value \\
\hline grid panel height & $600 \mathrm{~mm}$ \\
grid panel width & $800 \mathrm{~mm}$ \\
skin surface thickness & $1.5 \mathrm{~mm}$ \\
rib height & $30 \mathrm{~mm}$ \\
rib thickness & $3 \mathrm{~mm}$ \\
angle $\alpha$ of hoop ribs & $\pm 35 \mathrm{deg}$ \\
distance between hoop ribs & $108 \mathrm{~mm}$ \\
distance between helical ribs & $93.6 \mathrm{~mm}$ \\
grid panel mass & $5.125 \mathrm{~kg}$
\end{tabular}

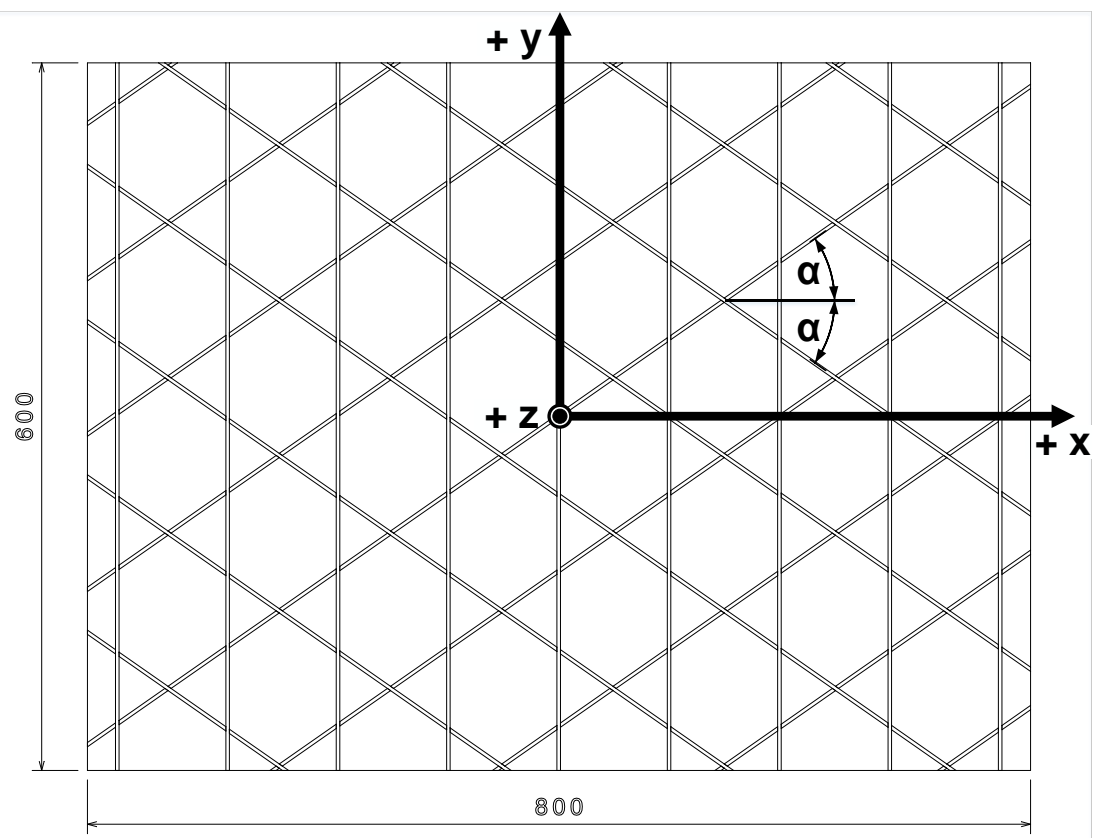

Figure 2: Schematic of the grid panel 


\subsection{Experimental modal analysis and numerical modeling}

First, a laboratory set-up is developed to determine the dynamic properties of the grid panel, which can additionally be used to realize a synthetic TBL excitation. As shown in Figure 1, the synthetic TBL excitation requires an additional validated numerical model. The final set-up is shown in Figure 3. It uses a soundproofed wooden box placed inside a semi-anechoic room. The grid panel is supported by four shock mounts, one in each corner (Continental Schwingmetallpuffer Typ A, Order No. 3911 206). The frame is sealed with an acoustic rubber lip and the box itself is filled with acoustic foam (not shown in Fig. 3) to damp the cavity modes. As excitation source, a shaker or an acoustic array of six unevenly distributed loudspeakers is used. To record the dynamical response of the grid panel, a scanning laser vibrometer (LSV) is utilized that scans 285 points evenly distributed on the test structure.

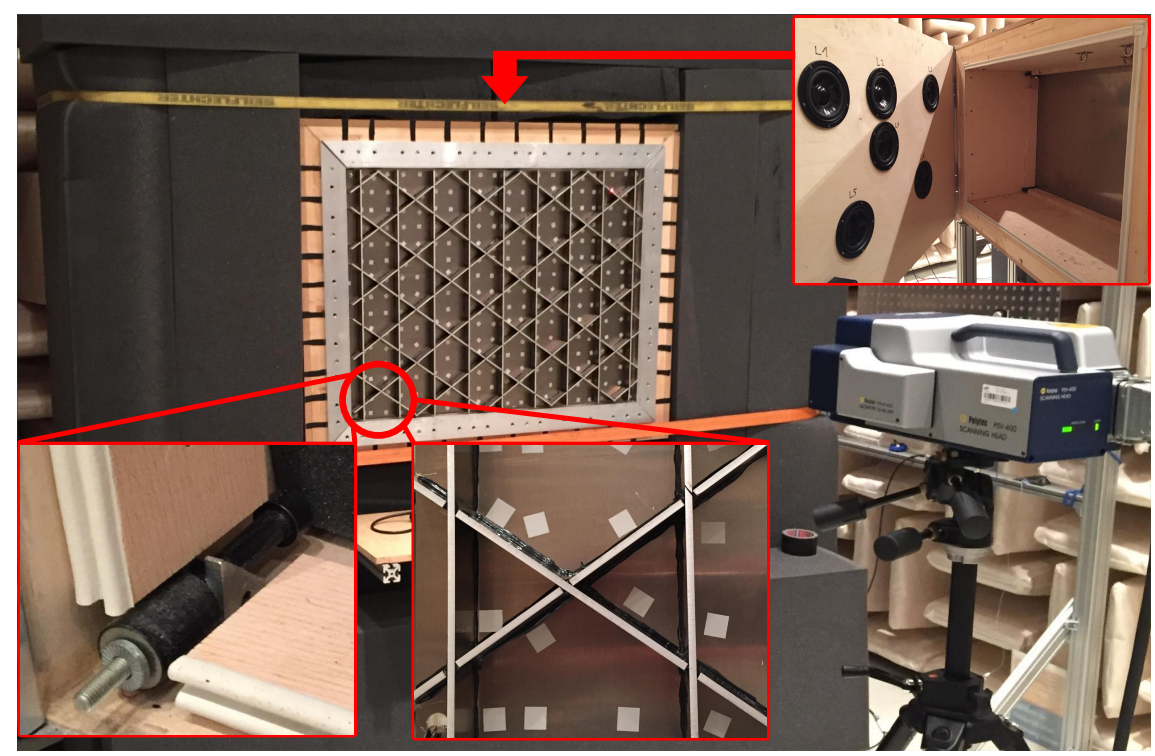

Figure 3: The picture of the experimental set-up shows the elastic support, the sealing, the LSV as well as the measuring points, the loudspeaker array and an enlarged view of the test structure showing the connection assembly of the ribs. The picture shows neither the acoustical foam inside the wooden box nor the shaker at the optimized position as excitation source for the EMA. 
This set-up and especially the bearing of the grid panel ensure a good correlation between the physical testing and the numerical simulations. The shock mounts are designed in such a way as to allow for a degree of isolation of $90 \%$ at $108 \mathrm{~Hz}$. This ensures a decoupling of support structure and test object within the frequency range of interest. The occuring rigid body modes are mode 1 to mode 3 shown in Table 3 ,

As a next step, an experimental modal analysis (EMA) is conducted. The aim is to identify all eigenfrequencies and mode shapes for the elastic supported grid panel up to $500 \mathrm{~Hz}$. As excitation source an elastically supported electrodynamic shaker is connected to the back of the grid panel at an optimized position. The optimized position is derived from the results of an initial modal analysis. In this position, the shaker is able to properly excite all eigenfrequencies up to $500 \mathrm{~Hz}$. The received experimental data is analyzed by means of the X-Modal III software. An examination of the Auto-MAC values for the identified mode shapes clearly shows that the test structure has 10 independent mode shapes for the chosen frequency range. All diagonal elements of the MAC matrix are equal to 1 . The secondary diagonal elements are in a range between 0 and 0.04 . Figure 5 shows the averaged frequency response function of all 285 measuring points for the conducted EMA. The eigenfrequencies are listed in Table 3 A comparison of the received mode shapes to the ones calculated in a numerical modal analysis for a grid panel with free boundary conditions confirms the decoupling of test and support structure for frequencies above $108 \mathrm{~Hz}$. For this reason the following research focuses on the modes 4-10 in the frequency range from $100 \mathrm{~Hz}$ to $500 \mathrm{~Hz}$.

The experimental data from the EMA is further used to update a numerical model of the grid panel in Ansys, using the optimization software optiSLang by Dynardo. To obtain a sufficient representation of the physical test specimen, the geometry is exactly modeled. Hence every rib, the aluminum plate and every adhesion layer at the intersection points of the ribs is described as a self-contained body. The shock mounts are modeled with COMBIN14 elements. For the entire structure, two linear-elastic, isotropic material models are used. 
The material model of the plate and the ribs is termed "Aluminum" and the one of the adhesive layers is termed "Adekit". To adequately update the numerical model with the experimental data, an affiliated point in the FE mesh is described for every measuring point. The model updating itself is conducted in two iterations. First, the eigenfrequencies and mode shapes are compared, while in the second step the damping behavior is adjusted. The updating process is based on a parameter optimization using the Hypercube Sampling as well as the Adaptive Response Surface Method implemented in optiSLang. For the first step, the densities and elastic modules of the material models as well as the stiffness of the COMBIN14 elements are optimized. The interval boundaries for the optimization and the resulting optimum for each parameter are listed in Table 2. The objective function is shown in Equation 1.

$$
\operatorname{obj} 1=\min \left(\sum_{i=4}^{10} \frac{\left|f_{\mathrm{FEM}, i}-f_{\mathrm{EMA}, i}\right|}{f_{\mathrm{EMA}, i}}+\sum_{i=4}^{10}\left|\mathrm{MAC}_{i}-1\right|\right) \frac{1}{14}
$$

Table 2: Interval limits of the optimization parameters of the first iteration

\begin{tabular}{cccc}
$\begin{array}{c}\text { optimization } \\
\text { parameter }\end{array}$ & lower limit & upper limit & optimized value \\
\hline$\rho_{\text {Adekit }}$ & $1000 \mathrm{~kg} / \mathrm{m}^{3}$ & $1400 \mathrm{~kg} / \mathrm{m}^{3}$ & $1157.3 \mathrm{~kg} / \mathrm{m}^{3}$ \\
$E_{\text {Adekit }}$ & $5 \mathrm{E} 08 \mathrm{~Pa}$ & $3 \mathrm{E} 10 \mathrm{~Pa}$ & $3 \mathrm{E} 9 \mathrm{~Pa}$ \\
$\rho_{\text {Aluminium }}$ & $2400 \mathrm{~kg} / \mathrm{m}^{3}$ & $3100 \mathrm{~kg} / \mathrm{m}^{3}$ & $2754.69 \mathrm{~kg} / \mathrm{m}^{3}$ \\
$E_{\text {Aluminium }}$ & $6 \mathrm{E} 10 \mathrm{~Pa}$ & $8 \mathrm{E} 10 \mathrm{~Pa}$ & $6.89 \mathrm{E} 10 \mathrm{~Pa}$ \\
$k_{\text {COMBIN14 }}$ & $30000 \mathrm{~N} / \mathrm{m}$ & $80000 \mathrm{~N} / \mathrm{m}$ & $79992.4 \mathrm{~N} / \mathrm{m}$
\end{tabular}

The goal of the first optimization step is the minimization of the deviations of the eigenfrequencies (comp. Table 3) and the mode shapes quantified by the Cross-MAC criterion (comp. Table 3) of the numerical model and the experimental set-up. By including modes 3 to 10, which are not coupled to the bearing of the grid panel, in the considered frequency range at the same time, the result constitutes a best fit. The results of the optimization presented in 
Table 3 show a good correlation between the numerical and the physical model. Only the results for the eigenfrequencies 9 and 10 show higher deviations. The mode shapes identified by the EMA are shown in Figure 4.

Table 3: Comparison of eigenfrequencies and mode shapes of FEM and EMA

\begin{tabular}{c|ccc|c}
\multirow{2}{*}{ Mode $n$} & \multicolumn{3}{|c|}{ Eigenfrequency } & Cross-MAC $\mathrm{MAn}_{n, n}$ \\
\hline 1 & EMA / Hz & FEM / Hz & Deviation & \\
2 & 37.15 & 32.46 & $-14.45 \%$ & 0.99 \\
3 & 61.02 & 56.70 & $-7.62 \%$ & 0.93 \\
4 & 71.26 & 60.35 & $-18.08 \%$ & 0.91 \\
5 & 152.74 & 150.78 & $-1.30 \%$ & 0.94 \\
6 & 168.19 & 164.70 & $-2.12 \%$ & 0.95 \\
7 & 296.51 & 300.51 & $+1.33 \%$ & 0.99 \\
8 & 360.67 & 360.26 & $-0.11 \%$ & 0.99 \\
9 & 381.86 & 381.81 & $-0.01 \%$ & 0.99 \\
10 & 457.52 & 482.05 & $+5.09 \%$ & 0.91 \\
& 466.84 & 486.88 & $+4.12 \%$ & 0.89
\end{tabular}

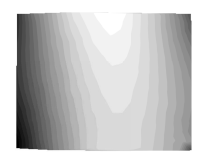

(a)

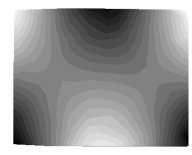

(f)

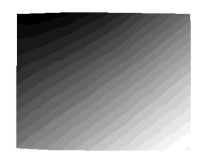

(b)

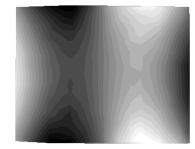

(g)

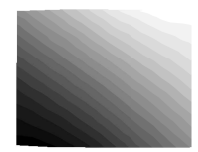

(c)

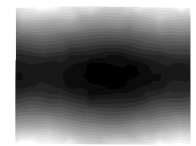

(h)

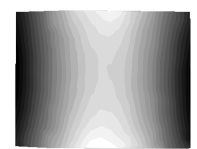

(d)

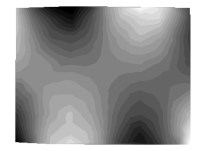

(i)

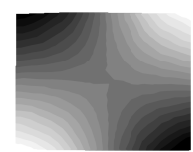

(e)

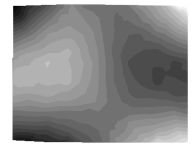

(j)

Figure 4: Representation of mode shape 1 (a) to mode shape 10 (j) of the grid panel.

To adapt the damping behavior of the numerical model in the following step, the Rayleigh damping coefficients on the material level and the damping 
of the COMBIN14 elements are optimized inside Ansys. The objective function obj2 aims to minimize the deviation of the averaged amplitudes of the FRF at the locations of the eigenfrequencies from the numerical and the experimental model.

$$
\operatorname{obj} 2=\min \left(\sqrt{\frac{\sum_{i=4}^{10}\left(\overline{H 1}_{\mathrm{EMA}, i}-\overline{H 1}_{\mathrm{FEM}, i}\right)^{2}}{7}}\right)
$$

Using the root-mean-square-error (Equation 2), the optimized results in Table 4 present again a best fit for all relevant modes. A comparison of the averaged frequency response functions is displayed in Figure 5. Apart from the values of the eigenfrequencies 9 and 10 and the amplitude around eigenfrequency 7 , the numerical model shows a good correlation with the experimental one.

Table 4: Interval limits of the optimization parameters of the second iteration

\begin{tabular}{cccc}
$\begin{array}{c}\text { optimization } \\
\text { parameter }\end{array}$ & lower limit & upper limit & optimized value \\
\hline$\alpha_{\text {Adekit }}$ & 0 & 315 & 0 \\
$\beta_{\text {Adekit }}$ & 0 & $1.6 \mathrm{E}-4$ & $3.94 \mathrm{E}-5$ \\
$\alpha_{\text {Aluminium }}$ & 0 & 160 & 25.89 \\
$\beta_{\text {Aluminium }}$ & 0 & $8 \mathrm{E}-05$ & 0 \\
$d_{\text {COMBIN14 }}$ & $0 \mathrm{Ns} / \mathrm{m}$ & $0.5 \mathrm{Ns} / \mathrm{m}$ & $0.005 \mathrm{Ns} / \mathrm{m}$
\end{tabular}

\subsection{Imitation of a TBL excitation in the laboratory}

To enable a physical testing of the effect of PCLD applications to the grid panel under a TBL excitation, a laboratory set-up is needed, which imitates it as accurately as possible. The procedure applied in this paper is taken from [12]. It aims at calculating excitation signals for a specified number of sources so as to generate the same surface velocities for a given structure as would occur under a TBL excitation. As excitation source the described loudspeaker array (LSA) with six sources is utilized. Figure 6 describes the process of the laboratory TBL pressure field synthesis in a block diagram form. The system $\mathbf{F}$ represents the experimental setup shown in Figure 3 including the loudspeaker array (LSA), 


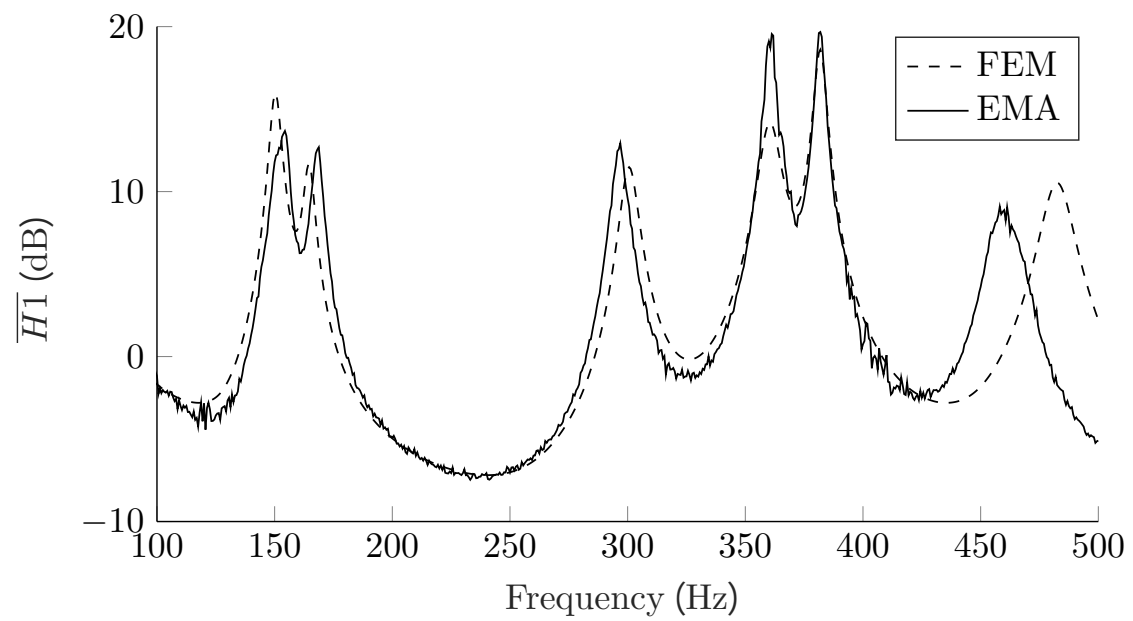

Figure 5: Comparison of the magnitude of the averaged frequency response functions calculated from the experimental results of the EMA (target) and the simulation results of optimized FEM model (achieved)

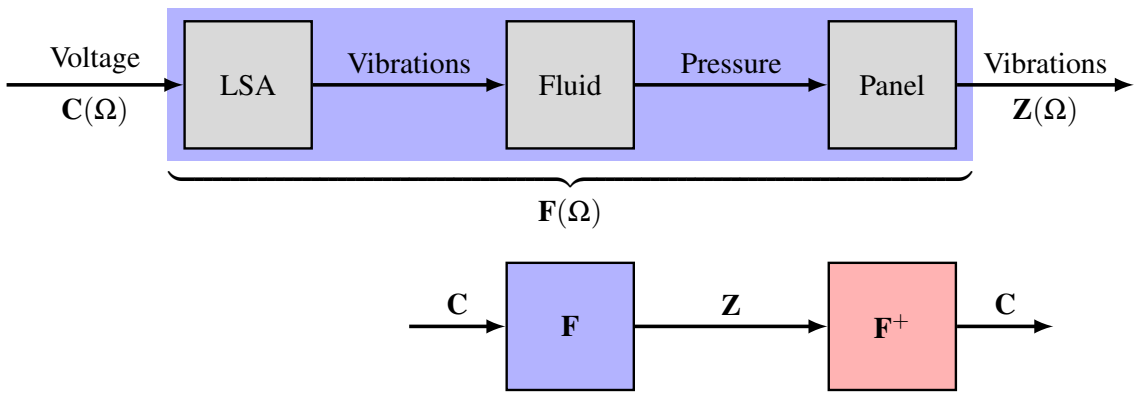

Figure 6: Block diagram of the laboratory TBL pressure field synthesis. 
the fluid inside the wooden box and the grid panel. The goal is to find control voltages $\mathbf{C}$ for the LSA such that a prescribed structural vibration $\mathbf{Z}$ is achieved. Here, $\mathbf{Z}$ comes from the simulation of a validated structural model excited by a TBL pressure field. It is known from prior work [13, 14, 15, 16, 17, 18, 19] that the direct synthesis of the TBL pressure field is difficult to achieve having a limited number of loudspeakers and a limited source density. Therefore, it is decided to emulate the structural vibration instead. However, the benefit of structural wave number filtering comes at the cost of having the structure inside of the system $\mathbf{F}$. Therefore, knowledge of the structural dynamics is required to calculate the target vibration $\mathbf{Z}$. Furthermore, the frequency responses of the physical system $\mathbf{F}$ must be measured. Having $\mathbf{Z}$ and the pseudo-inverse $\mathbf{F}^{+}$of $\mathbf{F}$, the control voltages $\mathbf{C}$ are readily obtained. More details on the laboratory TBL synthesis including a validation with measurement data from an aeroacoustic wind tunnel can be found in [12.

As described, the laboratory TBL synthesis requires a numerical model of the structure under consideration, a TBL model and the FRF matrix of system F. The derivation of a valid numerical model of the structure is described in subsection 2.2. The FRF matrix of $\mathbf{F}$ is obtained from sequential scans with a scanning laser vibrometer. The FRF is measured column-wise by doing one complete laser scan of all 285 measuring points for each loudspeaker. The TBL pressures are obtained from a Corcos model (see [20]). The parametrization of this model will be explained in the following.

According to the Corcos model, the cross-power spectral density (CPSD) of two pressure signals $\mathrm{x}$ and $\mathrm{y}$ measured in a fully developed TBL is given by

$$
S_{\mathrm{xy}}\left(\omega, r_{\mathrm{sp}}, r_{\mathrm{st}}\right)=S_{\mathrm{xx}}(\omega) \underbrace{\mathrm{e}^{-\left|r_{\mathrm{sp}}\right| / L_{\mathrm{sp}}(\omega)}}_{B\left(\omega, r_{\mathrm{sp}}\right)} \underbrace{\mathrm{e}^{-\left|r_{\mathrm{st}}\right| / L_{\mathrm{st}}(\omega)}}_{A\left(\omega, r_{\mathrm{st}}\right)} \mathrm{e}^{-\mathrm{j} \omega r_{\mathrm{st}} / U_{c}} .
$$

In this formula $S_{\mathrm{xx}}$ describes the power spectral density (PSD) of $x$ which is assumed to be identical at any point in the TBL pressure field. This is true when the TBL grows slowly and when the TBL pressure field is homogenous. 
wind tunnel [21]. Figure 7a shows the PSD in the considered frequency range for a flow velocity of $62.4 \mathrm{~m} \mathrm{~s}$. A plot of the PSD for different velocities is given in $\mathrm{Hu}$ and Misol [21, Fig. 5]. Below $200 \mathrm{~Hz}$ the PSD is contaminated with noise which is attributed to the open-jet free shear-layers of the experimental setup. A comparison with flight-test data suggests a more flat PSD in the considered frequency range with higher amplitude at cruise speed [22, Fig. 11]. The distances between two points in the span- and streamwise directions are $r_{\mathrm{sp}}$ and $r_{\mathrm{st}}$ and the corresponding correlation lengths are $L_{\mathrm{sp}}$ and $L_{\mathrm{st}} . U_{c}$ is the convection velocity of the TBL pressure field. A value of $135 \mathrm{~m} \mathrm{~s}$ is assumed for $U_{c}$ which corresponds to a free-stream velocity of about $225 \mathrm{~m} \mathrm{~s}$ and a Mach number of $M \approx 0.66$ [14]. The correlation lengths are defined as $L_{\mathrm{sp} / \mathrm{st}}=\alpha_{\mathrm{sp} / \mathrm{st}} U_{c} \omega^{-1}$. The $\alpha$-values are also taken from Elliott et al. [14] where they are defined as $\alpha_{\mathrm{sp}}=1.2$ and $\alpha_{\mathrm{st}}=8$. It should be noted, that these values slightly differ from the $\alpha$-values documented in Hu and Herr [23] which are $\alpha_{\mathrm{sp}} \approx 1.4$ and $\alpha_{\mathrm{st}}$ in the range 7 to 10 (depending on the Reynolds number). The correlation structure of the TBL for the chosen parameters is shown in Fig. 7b. A streamwise separation of $r_{\mathrm{st}}=0.8 \mathrm{~m}$ and a spanwise separation of $r_{\mathrm{sp}}=0.6 \mathrm{~m}$ is chosen for this plot.

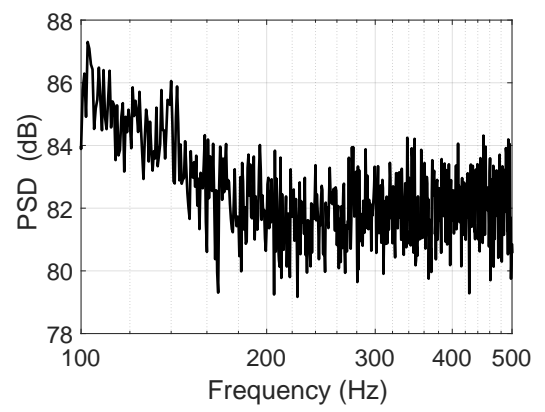

(a)

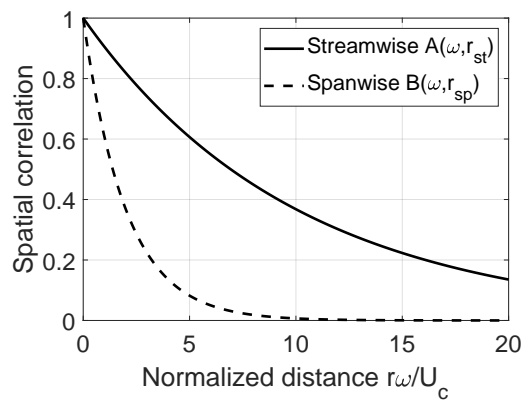

(b)

Figure 7: (a) PSD and (b) normalised magnitudes of the spatial correlation functions of the prescribed TBL excitation.

From the parameterized Corcos TBL model it is possible to derive the re- 
quired nodal forces for a discretized surface. The process of calculating a set of nodal pressures from Equation (3) requires an eigenvalue decomposition of $S_{\mathrm{xy}}$ [12, Eq. (4)]. The skin surface of the grid panel is discretized with 1271 nodes and the nodal forces are calculated for the frequency range from $100 \mathrm{~Hz}$ to $500 \mathrm{~Hz}$ with a frequency resolution of $0.625 \mathrm{~Hz}$. These nodal forces are applied to the affiliated points of the FE mesh and a numerical harmonic response analysis is conducted. As a result the normal surface velocities $\mathbf{Z}$ for the 285 measuring points, which represent the dynamic behavior of the grid panel under TBL-excitation, are extracted.

To evaluate the accuracy of the normal surface velocity distributions occuring in laboratory set-up with the TBL excitation, they are compared to the target ones by using the MAC criterion and the Rayleigh integral. The MAC criterion is able to quantify the linear dependency of the normal surface velocity vector achieved in the experiments and the vector of target values. The criterion thus allows the comparison of the resulting operational deflection shapes with those required. MAC values of 0.8 or higher are considered acceptable. This criterion is met at 321 frequency lines from 640 frequency lines in the frequency range of interest. To also capture the dependency of location, relative phase and amplitude of the normal surface velocities, the Rayleigh integral is evaluated for the experimental and for the target velocity distributions. As maximum permissible deviation, $1.5 \mathrm{~dB}$ is defined. This criterion is met at 212 frequency lines. The applicability of the Rayleigh integral had been verified during the EMA by comparing the results of the Rayleigh integral to those of a sound intensity measurement. Only 105 frequency lines meet both criteria. They are depicted in Figure 8 as dots. The Figure compares the radiated sound power calculated with the Rayleigh integral based on the experimentally measured normal surface velocity distributions on the one hand and those numerically simulated on the other hand. The chart shows some significant differences, which can be attributed to an insufficient laboratory set-up and the omission of the frequency shift for eigenfrequencies 8 and 9 between the physical test specimen and the numerical model. A more densely stacked loudspeaker array with 
evenly distributed sound sources closer to the grid panel and not coupling into a cavity would better preserve the results. Also there are issues with foreign noise and structure-borne noise bridges. Overall, there are sufficient appropriate frequency lines distributed throughout the frequency range to examine the dynamic behavior of the grid panel under a synthetic TBL excitation.

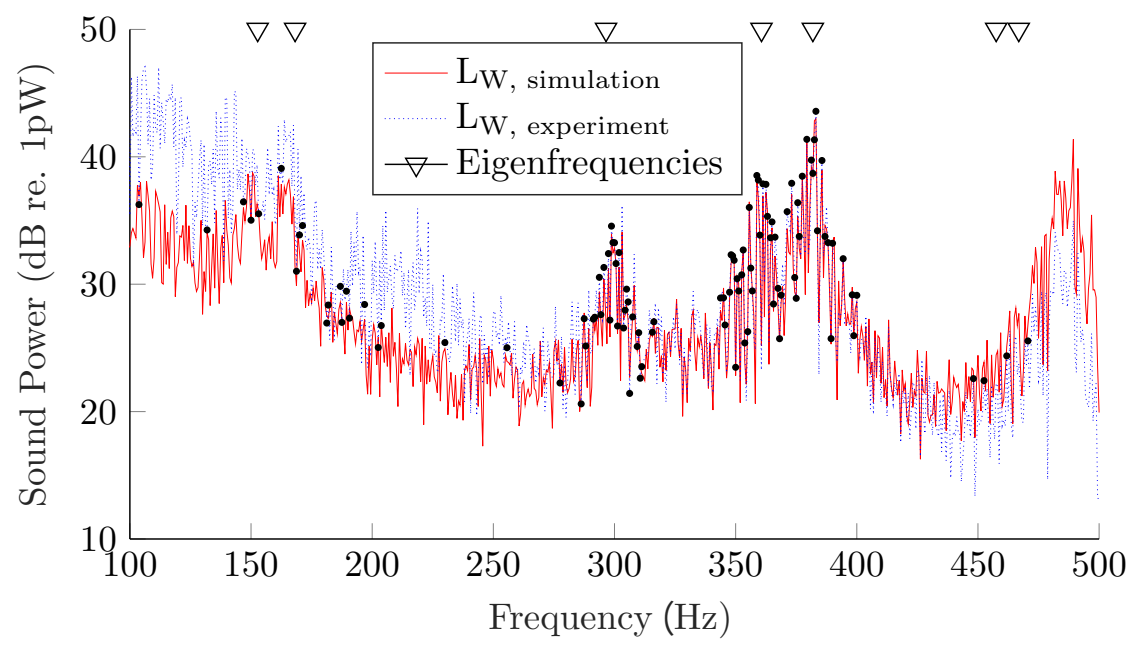

Figure 8: Radiated sound power based on the numerical simulation (target) compared to the experimentally reproduced sound power in a laboratory set-up (achieved) for the grid panel under synthetic TBL excitation. Frequency lines for which a successfull TBL synthesis could be implemented are marked with a dot.

\section{Assessment of vibroacoustical behavior and the influence of PCLD application for the grid panel}

This section examines the necessity for countermeasures concerning the radiated sound power of a grid panel under broadband excitation. Furthermore, it shows how configurations of different surface coverages of the grid panel with PCLD were developed using the modal strain energy method. Based on the synthetic TBL excitation, the influence of these PCLD applications regarding the radiated sound power is evaluated experimentally. 


\subsection{Sound radiation of the grid panel compared to that of ordinary plates}

Prior to the application of passive damping to the grid panel, the focus is on the characteristic dynamic behavior under synthetic TBL excitation. For that purpose, the radiated sound power as well as the radiation efficiency are compared to those of two flat plates made from aluminum with the same height and width as the grid panel. The first plate has a thickness of $1.5 \mathrm{~mm}$ and represents the skin of the grid panel without any ribs. The second plate has mass identical to that of the grid panel, which equates a thickness of $4.07 \mathrm{~mm}$. The results, which are presented in Figure 9, are based on numerical studies evaluated with the Rayleigh integral. The radiation efficiency can be calculated by dividing the radiated sound power $W$, calculated by the Rayleigh Integral, with the one which would occur, when a rigid piston radiator with an equal area $S$ is oscillating with time- and spatially- averaged surface velocity $\tilde{v}$ using Equation 4.

$$
\sigma=\frac{W}{W_{0}}=\frac{W}{\rho_{0} c_{0} \tilde{v}^{2} \sum S_{E, n}}, \text { with } \tilde{v}^{2}=\sum_{n=1}^{N} \frac{v_{n}^{2}}{2} \frac{S_{E, n}}{\sum S_{E, n}}
$$
used to calculate the Rayleigh Integral are used. They clearly show the necessity of sound reduction measures for the grid panel. Even at low frequencies, the grid panel has a significantly increased radiation efficiency. In addition, the grid panel shows a distinct resonance behavior in the area of its eigenfrequencies. frequencies in the range from $100 \mathrm{~Hz}$ to $500 \mathrm{~Hz}$ and the related mode shapes have a low order.

In the following, some general effects of acoustic and hydrodynamic coincidence are discussed. At the acoustic coincidence frequency $f_{q}$ fluid wave lenght and bending wave lenght of the plate are identical. This leads to a drop in the transmission loss of the plate. Also acoustic short-circuit can only occur for frequencies below $f_{g}$. In addition the well known mass law of BERGER, which states that a doubling of the area-related mass leads to an increase of the 
transmission loss by $6 \mathrm{~dB}$, is only valid below the coincidence frequency. The coincidence frequency of an ordinary plate can be calculated using Equation 5 .

$$
f_{g}=\frac{c^{2}}{2 \pi h} \sqrt{\frac{12\left(1-\nu^{2}\right) \rho}{E}}
$$

With a speed of sound $c=343 \mathrm{~m} \mathrm{~s}$, the plate thickness $h=1.5 \mid 4.07 \mathrm{~mm}$, a density $\rho=2700 \mathrm{~kg} \mathrm{~m}^{3}$, a Poisson ratio $\nu=0.34$ and a Young's modulus $E=70 \mathrm{GPa}$ the coincidence frequency for the $1.5 \mathrm{~mm}$ thick aluminium plate is found to be $7987 \mathrm{~Hz}$ and the one for the $4.07 \mathrm{~mm}$ thick plate $2943 \mathrm{~Hz}$.

An exact calculation of the acoustic coincidence frequency for the grid panel is more difficult. For the purpose of the present work, it is of main interest, whether the acoustic coincidence falls within the considered frequency range. Therefore, the authors choose an approach to estimate the coincidence frequency by analyzing the wave numbers of symmetric mode shapes. This is done by calculating all mode shapes up to $1500 \mathrm{~Hz}$ using the optimized FEMModel and then fitting an $A * \sqrt{f}$ function to the identified symmetric modes, since the bending wave velocity is proportional to the square root function of the frequency $f$. For example the mode shape at frequency $381.86 \mathrm{~Hz}$ displayed in Figure 4 4 shows one wavelenght in $\mathrm{y}$-direction and none in $\mathrm{x}$-direction. By dividing the angular frequency with the resulting absolute value of the wave number, the bending wave speed is calculated. This is done for several supporting points. This method is found to be more appropriate compared to a wave number analysis which has a very low wavenumber resolution because of the small grid panel dimensions. The fitted curve can be used to identify the frequency belonging to a bending wave velocity of $343 \mathrm{~m} \mathrm{~s}$. This method does not provide an exact calculation of $f_{g}$ but is able to estimate the range of the acoustic coincidence effect to be expected. The results are shown in Figure 10 250 The acoustic coincidence frequency for the grid panel is found to be around a frequency of $1016 \mathrm{~Hz}$ and therefore beyond the considered frequency range. Also the radiation efficiency displayed in Figure $9 \mathrm{~b}$ is below $0 \mathrm{~dB}$ and therefore indicates acoustic short-circuit effects are present in the frequency range till 500 $\mathrm{Hz}$, which suggests that the acoustic coincidence effect is outside the considered 
range.

Beside the acoustic coincidence frequency also the hydrodynamic coincidence frequency is of interest. This coincidence effect is related to the specific convection velocity of the TBL pressure field. At this frequency an enhanced coupling of the external excitation to the structure is possible and thus the transmission loss decreases and the radiated sound power increases. With a convection velocity of $U_{c}=135 \mathrm{~m} \mathrm{~s}$ the hydrodynamic coincidence frequency using Equation 5 for the $1.5 \mathrm{~mm}$ thick plate can be found at $1237 \mathrm{~Hz}$ and the one for the 4.07 $\mathrm{mm}$ thick plate at $456 \mathrm{~Hz}$. The closest eigenfrequencies of the $4.07 \mathrm{~mm}$ thick plate are calculated to be at $430.3 \mathrm{~Hz}$ and $468 \mathrm{~Hz}$. The mode shape of the 468 $\mathrm{Hz}$ eigenfrequency shows continous vibration maxima and minima oriented only along the x-axis of the grid panel. This explains the high gain of the radiated sound power shown in Figure 9a. For the grid panel the fitted bending wave velocity function is used to calculate the hydrodynamic coincidence frequency which is around $157.4 \mathrm{~Hz}$. This may explain the high amplitudes received for the low order modes $4(152.74 \mathrm{~Hz})$ and $5(168.19 \mathrm{~Hz})$ of the grid panel under TBL-excitation (comp. Figure 9a).

Summerizing it can be stated that the effect of acoustic coincidence is not present within the considered frequency range but the hydrodynamic coincidence is. A grid panel made from CFRP may also shift the acoustic coincidence frequency 275 to a value below $500 \mathrm{~Hz}$ because of the higher stiffness to mass ration (comp. Equation 5). The efficiency of PCLD measures would be amplified by the occuring drop in the transmisssion loss and the resulting higher vibration amplitudes. Therefore the tranferability of the results discussed in Section 3.2 is maintained. 


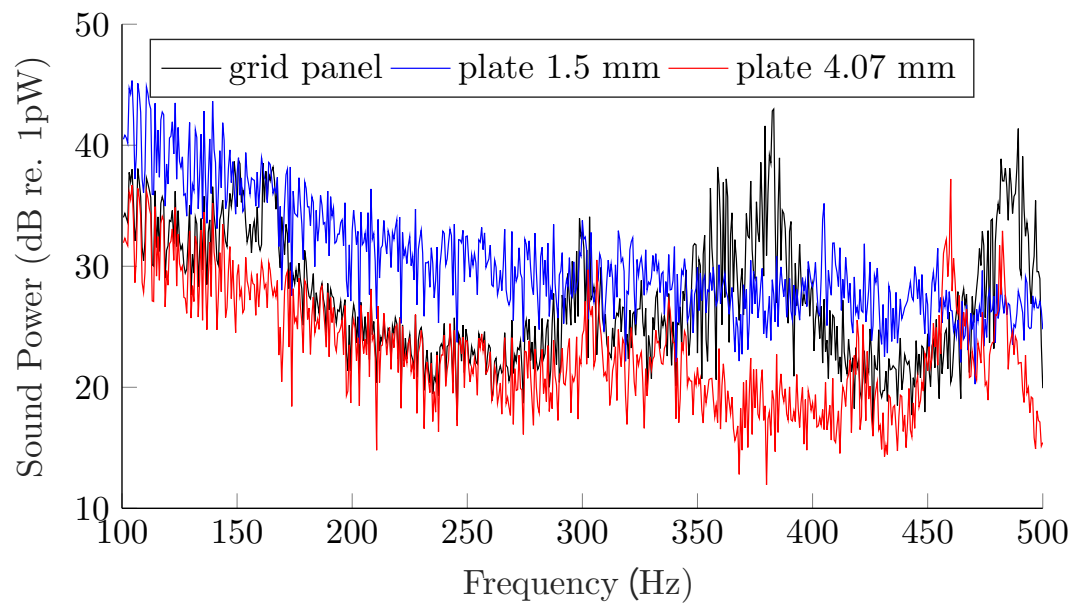

(a)

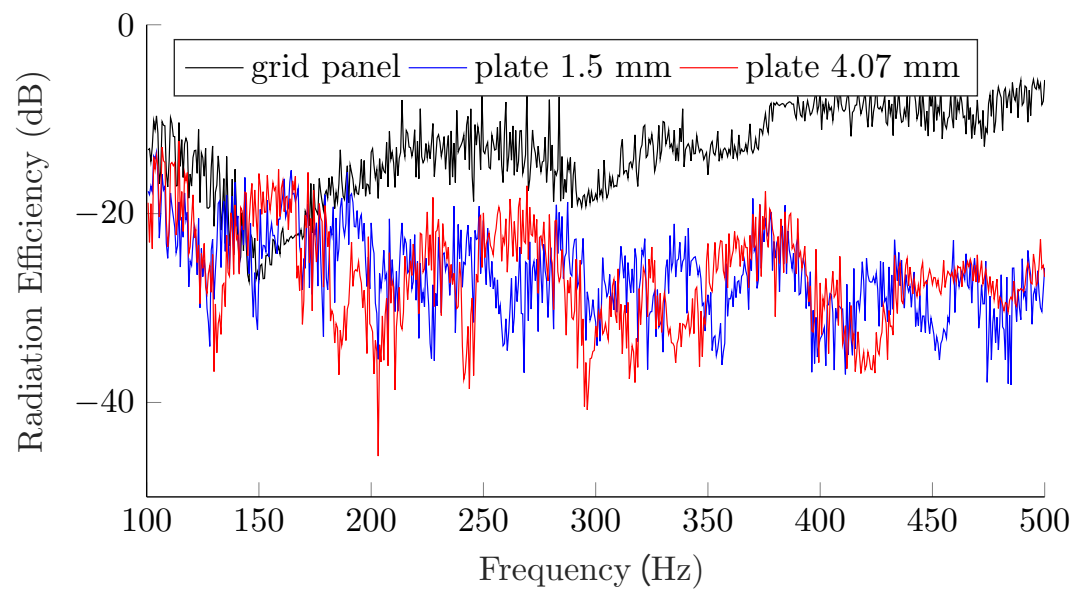

(b)

Figure 9: Examination of the vibroacoustical behavior of the grid panel under a synthetic TBL excitation in comparison to a plate representing only the skin of the grid panel and a mass-equivalent plate: (a) Comparison of active sound power; (b) Comparison of radiation efficiency 


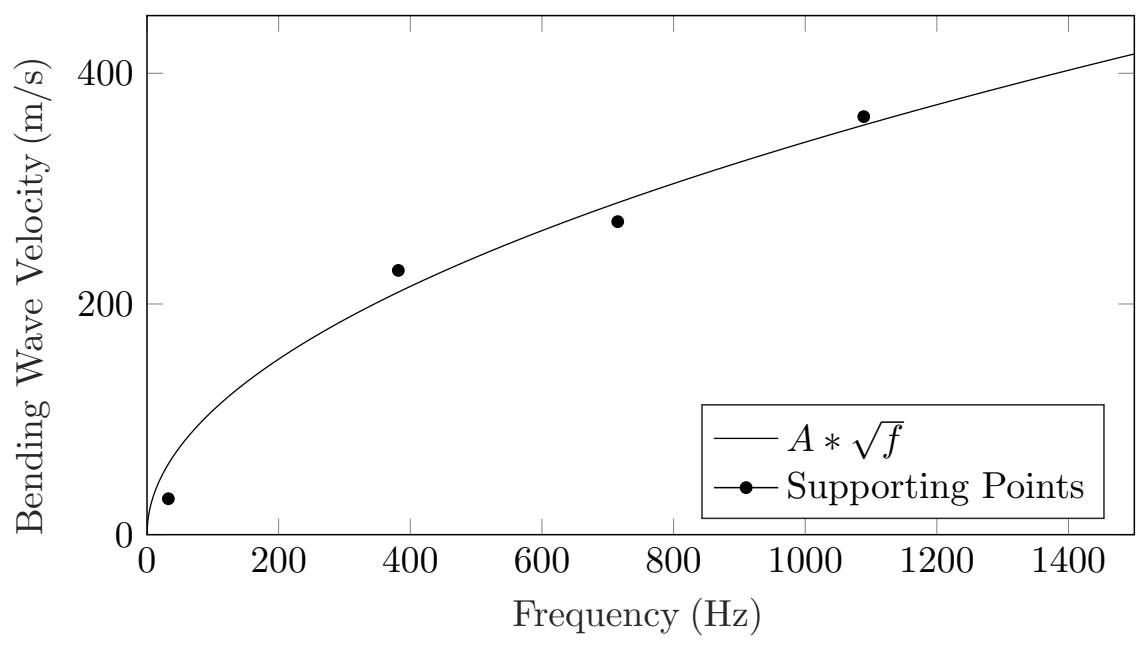

Figure 10: Fitted bending wave velocity function for the grid panel. 


\subsection{Application of PCLD measures to the grid panel} grid panel regarding its sound radiation characteristics. A simple PCLD configuration is a viscoelastic layer applied to a flexural vibration surface. The upper side of this layer is constrained by another layer with a highly increased stiffness in relation to the viscoelastic layer. This leads to additional shear deformations

calculated distributions need to be superposed. In the case of the grid panel, the modal strain energy distributions are calculated with the numerical model inside Ansys. Afterwards, the modes 4-10, which lie in the frequency range of 

for a mass gain of $10 \%$. Any additional influence can be related to the viscoelastic damping of the PCLD.

The described configurations of PCLD coverage are applied to the experimental 340

interest from $100 \mathrm{~Hz}$ to $500 \mathrm{~Hz}$, are superposed with the same weighting. This is realized by normalizing the MSE for the elements in the discretized numerical model of each eigenmode from 0 to 1 . This ensures that, for each eigenmode and each element, there is a value between 0 and 1, in which 1 represents the location of the highest MSE for a special eigenmode. These normalized values ensure that the different eigenmodes are weighted equally while superposing. It is of major importance, that the calculated strain energies are related to the surface strains, which are significantly responsible for the shear deformation inside the viscoelastic layer and thus for the damping efficiency. The resulting accumulated MSE distribution shows its highest values at the outer part of the ribs. For the following experimental study, eight configurations are derived from this MSE distribution. Between the different configurations, the percentage of surface coverage is gradually increased until the entire surface of the grid panel is covered. They all have in common, that always the locations with the highest MSE are incorporated. One exception are the surfaces of the ribs. Because of the in-plane bending, only the 3-mm-wide front surfaces and a stripe of $10 \mathrm{~mm}$ width at both sides, starting at the upper edge and going down towards the grid panel skin, are involved as applications surface for the PCLD. In the first configuration, CLD 1, only one side of the ribs is covered with PCLD. The second configuration, CLD 2, entails coverage of both sides and the front surface of the ribs. After this, the skin areas are gradually added to the coverage zone, until the whole surface of the grid panel is covered (CLD 5-4). This equates to a mass gain of $10 \%$ of the original panel without damping treatment. The different configurations are shown in Figure 11. As a general expectation the influence of the PCLD treatments should at least be in the range of the BERGER's mass 35 law, which would lead to an increase of the transmission loss of about $0.83 \mathrm{~dB}$ set-up with the synthetic TBL excitation. By evaluating the surface velocity 


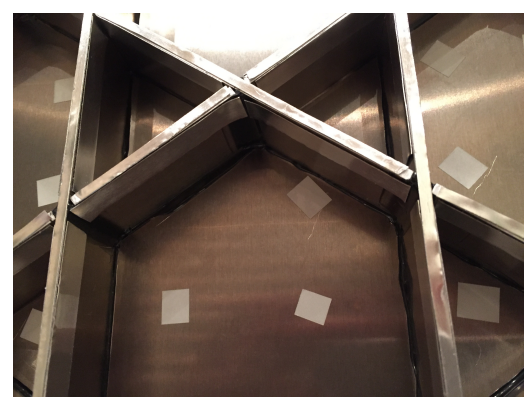

(a)

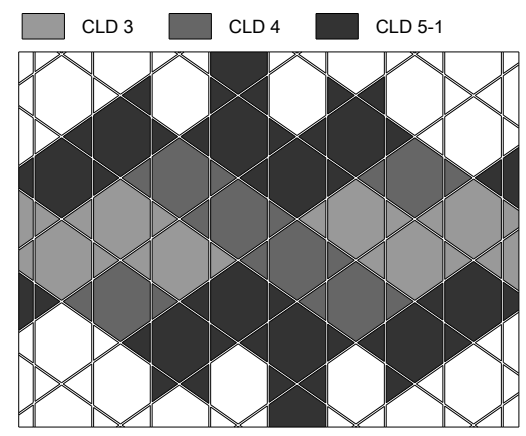

(c)

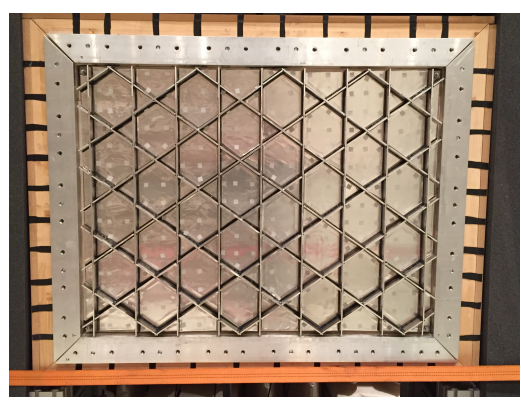

(b)

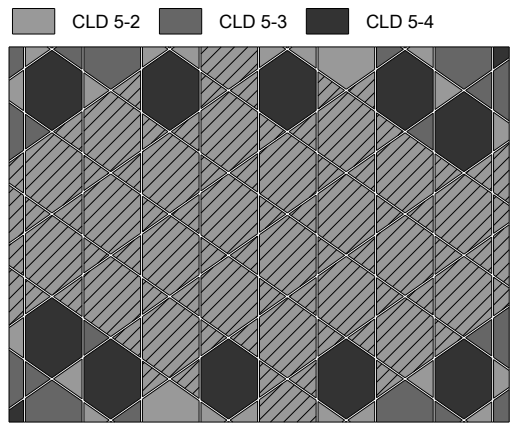

(d)

Figure 11: Display of the different PCLD configurations: (a) CLD 2, application of PCLD to the ribs; (b) CLD 5-4, total coverage with PCLD; (c)+(d) Display of the skin areas, which, in the marked configurations, covered with PCLD in addition to the ribs and the previous configuration

distributions with a LSV, the radiated sound power can be calculated with the Rayleigh integral. This radiated sound power is then compared to the one without any PCLD application in order to assess the influence of the PCLD by calculating the difference in radiated sound powers. For reasons of clarity, the results are displayed in a third-octave band representation. To allow for a general conclusion related to a TBL excitation, the received results are filtered by the 105 frequency lines for which a successful TBL synthesis can be confirmed. Compared to the unfiltered results, there are only slight differences in the third-octave band $160 \mathrm{~Hz}, 200 \mathrm{~Hz}, 315 \mathrm{~Hz}$ and $400 \mathrm{~Hz}$, which have an adequate frequency line denseness of the filtered spectrum. This is why, the 
following conclusions are based on the unfiltered results, which are assumed to be representative for a TBL-excitation. Figure 14 shows the changes in sound power levels for the eight CLD configurations. The change at each third-octave band is displayed at its center frequency, in which each first bar relates to the first configuration, CLD-1, and each last bar to the configuration CLD 5-4. As a general assessment it can be stated that the absolute change in the sound power level correlates with the total percentage of the surface covered with PCLD. Yet if the absolute change of the sound power level is associated with the added mass, there is no strict correlation. From one PCLD configuration to the next, there are always the locations of the highest MSE incorporated. Therefore, there should be a steady decrease in damping efficiency from configurations CLD 1 to CLD 5-4 configuration. To evaluate the exact effect of the PCLD application, the radiation efficiency as well as the effective averaged surface velocity spectrum are considered. Again, for reasons of clarity the change of these levels are shown in a third-octave band representation in Figure 13p. As this investigation shows, there are only small changes in the radiation efficiency but distinct changes in the surface velocities starting at a frequency of $300 \mathrm{~Hz}$. These velocity changes are essentially responsible for the sound power level changes, which can be attributed to two main effects. The first is an increased damping caused by the applied PCLD. The second is the shift of the eigenfrequencies and the increased transmission loss due to the added mass. The second effect might induce significant changes in third-octave band power if eigenfrequencies are shifted from one band to another (comp. Figure 12). This explains the increase of the sound power level in the $315 \mathrm{~Hz}$ third-octave band shown in Figure 14 375 It can generally be said that under the defined circumstances, an application of PCLD to the grid panel provides an additional damping, beginning with a frequency of $300 \mathrm{~Hz}$. This effect results in an overall reduction of the radiated sound power of up to $4 \mathrm{~dB}$ in the case of the $500 \mathrm{~Hz}$ third-octave band for the configuration CLD 5-4. It needs to be considered, that the effect in the $500 \mathrm{~Hz}$ third-octave band is amplified by the presence of two close eigenmodes, wich are dominating the response in the frequency range. 


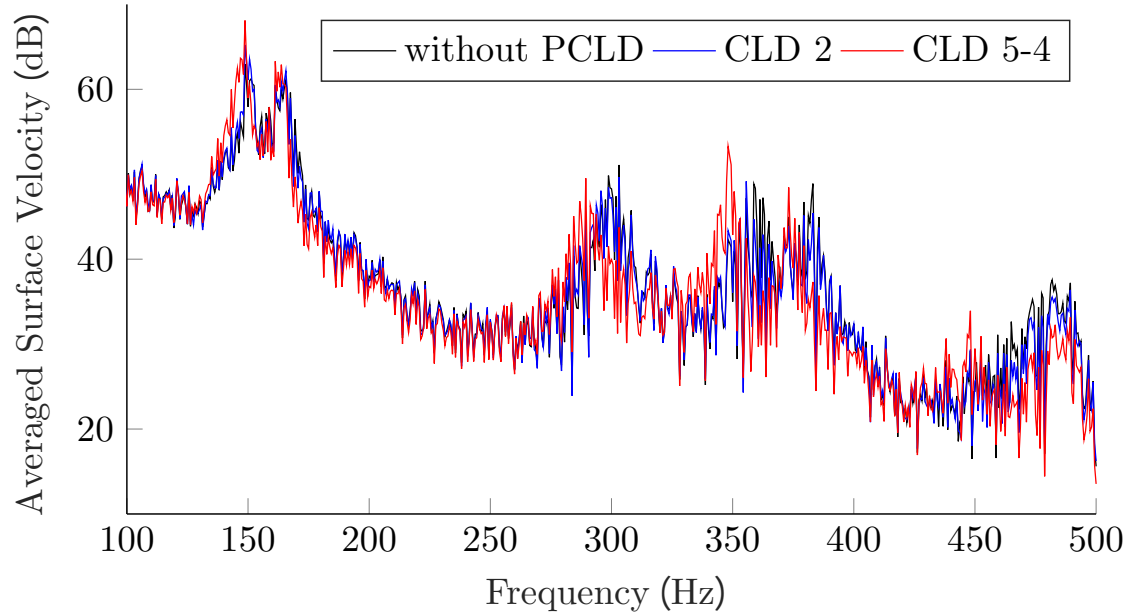

Figure 12: Representation of the averaged surface velocity for the grid panel with TBLexcitation without PCLD application and for the CLD2, CLD5-4 configurations 


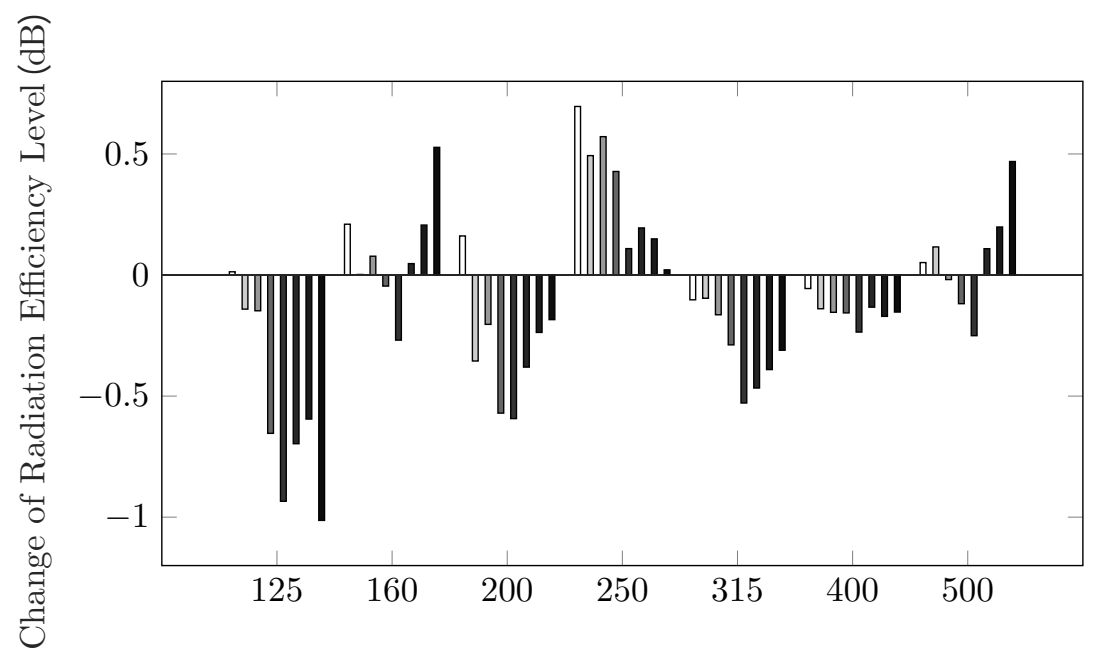

(a)

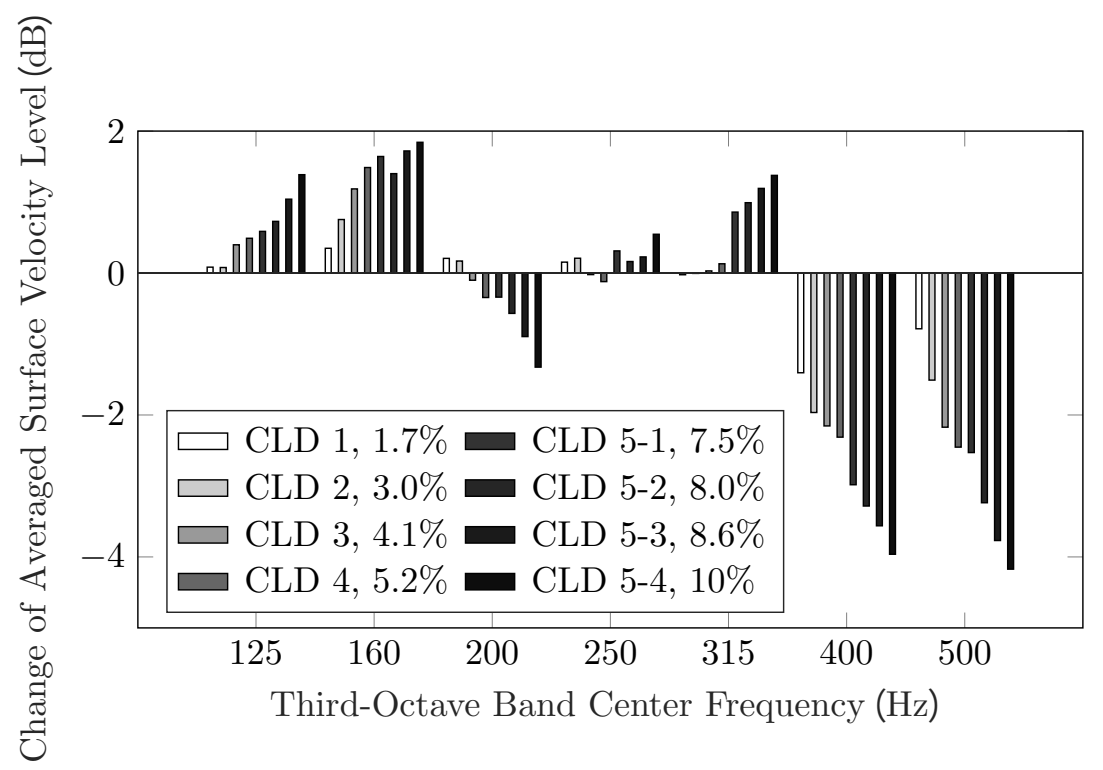

(b)

Figure 13: Comparison of radiation effeciency level and averaged surface velocity changes for the eight CLD configurations (the legend contains additional information about the mass gain): (a) Absolute radiation efficiency level change; (b) Absolute averaged surface velocity level change 


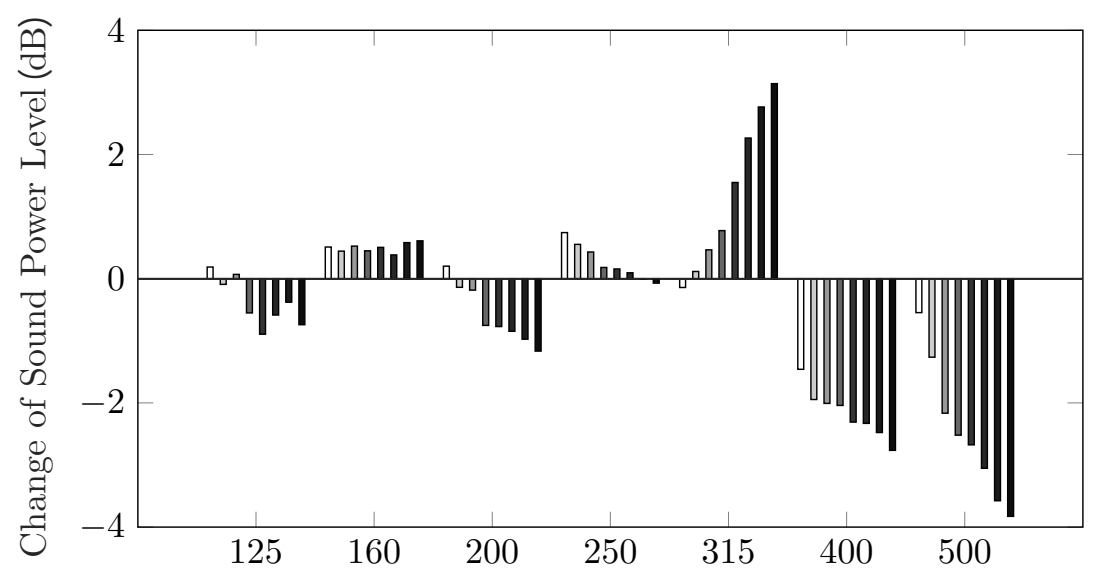

(a)

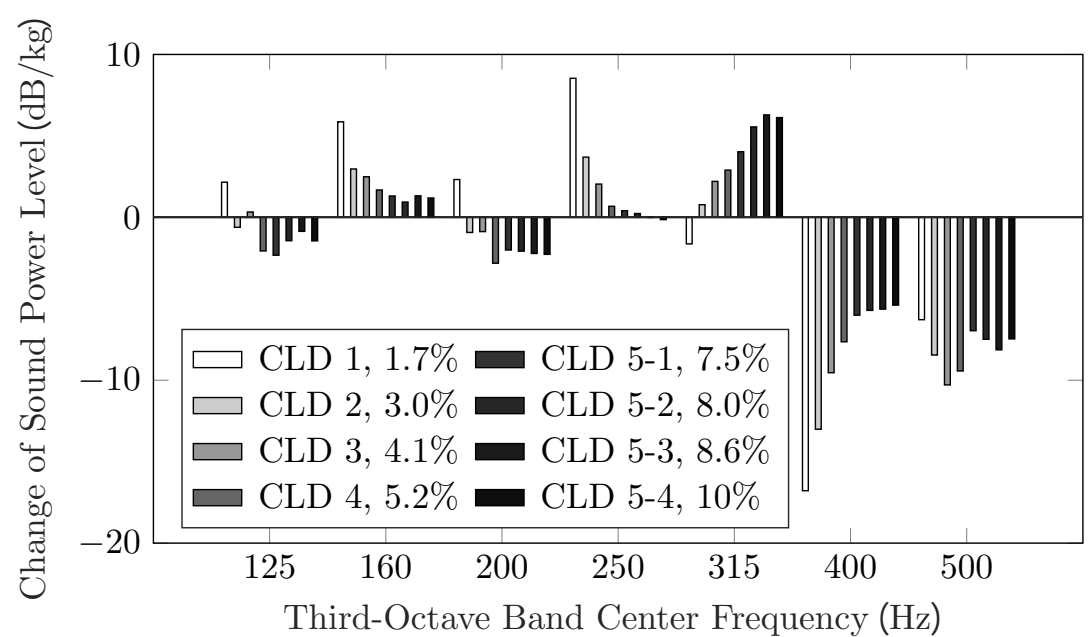

(b)

Figure 14: Comparison of sound power level changes for the eight CLD configurations (the legend contains additional information about the mass gain): (a) Absolute sound power level change; (b) Evaluation of damping efficiency by relating the absolute sound power level change to the added mass due to PCLD application 


\section{Conclusions}

This work provides a general study about the application of passive constrained layer damping (PCLD) to a grid panel and investigates its influence to citation. This is done by physical testing, aided by a validated numerical model. The numerical model is used for the implementation of a synthetic TBL excitation in a laboratory set-up, which is the load case for the PCLD treatments. Furthermore, the numerical model is used for the calculation of the modal strain 
TBL excitation are experimentally tested in [29]. For that purpose, the quality of the synthetic TBL excitation in the laboratory set-up is highly increased by using 12 evenly distributed lightweight inertial shakers as excitation sources. range seems to be a concept of active or active-passive-hybrid measures directly integrated into a longer stretch of the helical ribs.

\section{Acknowledgements}

Financial support has been provided by the German Research Foundation (DFG) in the framework of the SFB 880: Fundamentals of High Lift for Future Civil Aircraft.

\section{References}

[1] V. Vasiliev, V. Barynin, A. Razin, Anisogrid lattice structures - survey of development and application, Composite Structures 54 (2-3) (2001) 361370. doi:10.1016/s0263-8223(01)00111-8.

[2] V. Vasiliev, A. Razin, Anisogrid composite lattice structures for spacecraft and aircraft applications, Composite Structures 76 (1-2) (2006) 182-189. doi:10.1016/j.compstruct.2006.06.025

[3] V. Vasiliev, V. Barynin, A. Razin, Anisogrid composite lattice structures - development and aerospace applications, Composite Structures 94 (3) (2012) 1117-1127. doi:10.1016/j.compstruct.2011.10.023.

[4] V. Vasiliev, A. Razin, V. Nikityuk, Development of geodesic composite fuselage structure, International Review of Aerospace Engineering (IREASE) 7 (2014) 61-68.

[5] S. Niemann, B. Kolesnikov, H. Lohse-Busch, C. Hühne, O. M. Querin, V. V. Toropov, D. Liu, The use of topology optimisation in the conceptual design of next generation lattice composite aircraft fuselage struc- 
tures, The Aeronautical Journal 117 (1197) (2013) 1139-1154. doi: $10.1017 / \mathrm{s} 0001924000008745$

[6] R. Cordero, M. Aversano, Lattice composite structure development for small aircraft, in: ECCM16 - 16th European Conference on Composite Materials, Seville, Spain, 22-26 June 2014.

[ [7] F. E. Machtans, O. Unruh, Simulation des vibroakustischen verhaltens von

1. gridstrukturen (simulation of vibroacoustic behavior of grid stiffened panels). dlr-interner bericht. dlr-ib 131-2015/56, 61 s., Tech. rep.

URL http://elib.dlr.de/98443/

[8] M. L. Drake, J. L. Koury, T. D. Kim, J. A. Harvey, Integral acoustic control system for composite isogrid structures, in: N. W. Hagood, G. J. Knowles (Eds.), Smart Structures and Materials 1993: Smart Structures and Intelligent Systems, SPIE, 1993. doi:10.1117/12.152796.

„ [9] M. Titze, M. Misol, Analyse und beeinflussung der schallabstrahlung von

1. gitterversteiften paneelen (analysis and influence on sound radiation of grid stiffened panels). dlr-interner bericht. dlr-ib-fa-bs-2017-25, 81 s., Tech. rep., Deutsches Zentrum für Luft- und Raumfahrt (2017). URL http://elib.dlr.de/113975/

[10] J. S. Bevan, Piezoceramic actuator placement for acoustic control of panels, Tech. rep., Old Dominion University, Norfolk, Virginia, USA, NASA/CR2001-211265 (2001).

[11] H. P. Monner, M. Misol, S. Algermissen, O. Unruh, Active cfrp-panels for reduction of low-frequency turbulent boundary layer noise, in: Collection of Technical Papers - AIAA/ASME/ASCE/AHS/ASC Structures, Structural Dynamics and Materials Conference, American Institute of Aeronautics and Astronautics, Reston, Virginia, 2010.

URL http://elib.dlr.de/49287/ 
[13] C. Maury, S. J. Elliott, P. Gardonio, Turbulent boundary-layer simulation with an array of loudspeakers, AIAA Journal 42 (4) (2004) 706-713.

[14] S. J. Elliott, C. Maury, P. Gardonio, The synthesis of spatially correlated random pressure fields, The Journal of the Acoustical Society of America

[15] T. Bravo, C. Maury, The experimental synthesis of random pressure fields: Methodology, The Journal of the Acoustical Society of America 120 (5) (2006) 2702-2711. doi:10.1121/1.2354008.

[16] C. Maury, T. Bravo, The experimental synthesis of random pressure fields:

[12] M. Misol, S. Algermissen, N. Hu, H. P. Monner, Measurement, simulation and synthesis of turbulent-boundary-layer-induced vibrations of panel structures, in: K. Vogiatzis, G. Kouroussis, M. Crocker, M. Pawelczyk (Eds.), 23rd International Congress on Sound and Vibration, International Institute of Acoustics and Vibration (IIAV), 2016.

\section{URL https://elib.dlr.de/105844/} 117 (3) (2005) 1186-1201.

Practical feasibility, The Journal of the Acoustical Society of America 120 (5) (2006) 2712-2723. doi:10.1121/1.2354005

[17] T. Bravo, C. Maury, A synthesis approach for reproducing the response of aircraft panels to a turbulent boundary layer excitation, The Journal of the Acoustical Society of America 129 (1) (2011) 143-153.

[18] M. Aucejo, L. Maxit, J.-L. Guyader, Experimental simulation of turbulent boundary layer induced vibrations by using a synthetic array, Journal of Sound and Vibration 331 (16) (2012) 3824-3843.

[19] O. Robin, A. Berry, S. Moreau, Experimental vibroacoustic testing of plane panels using synthesized random pressure fields, The Journal of the Acoustical Society of America 135 (6) (2014) 3434-3445. 
[20] G. M. Corcos, Resolution of pressure in turbulence, The Journal of the Acoustical Society of America 35 (2) (1963) 192-199. doi:https: //doi.org/10.1121/1.1907821.

[21] N. Hu, M. Misol, Effects of riblet surfaces on boundary-layer-induced surface pressure fluctuations and surface vibration, in: Fortschritte der Akustik - DAGA 2015, 41. Deutsche Jahrestagung für Akustik, Deutsche Gesellschaft für Akustik e.V., Berlin, 2015.

[22] A. Klabes, C. Appel, M. Herr, M. Bouhaj, Fuselage excitation during cruise flight conditions: Measurement and prediction of pressure point spectra, in: AIAA Aviation, 21st AIAA/CEAS Aeroacoustics Conference, 2015.

URL http://elib.dlr.de/97218/

[23] N. Hu, M. Herr, Characteristics of wall pressure fluctuations for a flat plate turbulent boundary layer with pressure gradients, in: 22nd AIAA/CEAS Aeroacoustics Conference, 2016. URL http://elib.dlr.de/109083/

[24] E. M. Kerwin, Damping of flexural waves by a constrained viscoelastic layer, The Journal of the Acoustical Society of America 31 (7) (1959) 952962. doi:10.1121/1.1907821.

[25] B. M. Shafer, An overview of constrained-layer damping theory and application, ASA, 2013. doi:10.1121/1.4800606

[26] J.-L. Marcelin, P. Trompette, A. Smati, Optimal constrained layer damping with partial coverage, Finite Elements in Analysis and Design 12 (3-4) (1992) 273-280. doi:10.1016/0168-874x(92)90037-d.

[27] R. Plunkett, C. T. Lee, Length optimization for constrained viscoelastic layer damping, The Journal of the Acoustical Society of America 48 (1B) (1970) 150-161. doi:10.1121/1.1912112.

[28] J. Madeira, A. Araújo, C. M. Soares, C. M. Soares, Multiobjective optimization for vibration reduction in composite plate struc- 
tures using constrained layer damping, Computers \& Structuresdoi: 10.1016/j.compstruc. 2017.07 .012

[29] A. Lehn, M. Misol, Aktiv-passiv-hybride-methoden zur beeinflussung des 1. vibroakustischen verhaltens von gitterversteiften paneelen (active-passive-

0. hybrid methods to influence the vibroacoustic behavior of a grid stiffened panel.). dlr-interner bericht. dlr-ib-fa-bs-2017-218, 94 s., Tech. rep. (2017). 